CHRONIC OBSTRUCTIVE PULMONARY DISEASE

\title{
Early onset of effect of salmeterol and fluticasone propionate in chronic obstructive pulmonary disease
}

\author{
J Vestbo, R Pauwelst, J A Anderson, P Jones, P Calverley, on behalf of the TRISTAN study group
}

Thorax 2005;60:301-304. doi: 10.1136/thx.2004.025411

See end of article for authors' affiliations

Correspondence to:

Professor J Vestbo, North West Lung Centre,

Wythenshawe Hospital, Manchester M23 9LT, UK; jorgen.vestbo@ manchester.ac.uk

Received 22 March 2004 Accepted 19 January 2005
Background: Combined treatment with inhaled corticosteroids and long acting $\beta_{2}$ agonists is approved for the treatment of chronic obstructive pulmonary disease (COPD), but little is known about the onset of effect of the combination.

Methods: Data were used from 1465 patients with COPD entered into a large 1 year double blind trial with daily measurements of peak expiratory flow (PEF) and symptom scores.

Results: PEF was significantly higher after 1 day in patients treated with salmeterol $50 \mu \mathrm{g}$ twice daily or the salmeterol/fluticasone propionate combination 50/500 $\mu \mathrm{g}$ twice daily than placebo. In patients treated with fluticasone propionate $500 \mu \mathrm{g}$ twice daily alone, PEF differed from placebo after 2 days. The differences after 2 weeks compared with placebo were $16 \mathrm{l} / \mathrm{min}$ (95\% confidence interval (CI) 11 to 21), $11 \mathrm{l} / \mathrm{min}(95 \% \mathrm{Cl} 6$ to 16$)$, and $27 \mathrm{l} / \mathrm{min}$ (95\% Cl 22 to 33) for salmeterol, fluticasone propionate, and the salmeterol/fluticasone propionate combination, respectively. For all treatments the effect on PEF after 2 weeks was comparable to that seen at the end of the study. The difference between the salmeterol/ fluticasone propionate combination and placebo after 2 weeks as a percentage of baseline was similar for $\mathrm{PEF}$ and clinic forced expiratory volume in 1 second $\left(\mathrm{FEV}_{1}\right)$. Differences in breathlessness scores were statistically significant after 1 day for the group treated with salmeterol alone and after 2 days for the combination group. The 2 week change in $\mathrm{FEV}_{1}$ was only partly indicative of a long term response in individual patients.

Conclusions: The effects of salmeterol and fluticasone propionate, alone or in combination, on PEF and breathlessness are seen within days and most of the obtainable effect on these parameters is reached within 2 weeks.
$\mathrm{T}$ he Global Initiative for Chronic Obstructive Lung Disease (GOLD) guidelines for chronic obstructive pulmonary disease (COPD) recommend treatment with both inhaled corticosteroids and long acting bronchodilators for patients with moderate to very severe COPD with a history of exacerbations. ${ }^{1}$ These recommendations are based on an increasing number of large controlled trials lasting 636 months. The effects of inhaled corticosteroids are mainly due to a decrease in the number of exacerbations and a slowing down in the decline in health status; ${ }^{2-4}$ to date, little attention has been focused on whether an initial improvement in lung function provides symptomatic benefit, in particular a decrease in breathlessness. Long acting bronchodilators lead to an increase in lung function and fewer symptoms, as shown in several studies. ${ }^{5-9}$ In spite of the increasing evidence of efficacy of these treatments, little is known about how quickly their effects become evident. Drug action is conventionally thought to have a relatively rapid onset of effect in patients with bronchial asthma, but little is known about what happens in COPD and whether addition of an inhaled corticosteroid has any effect. In the recently published TRISTAN trial there seemed to be a rapid onset of effects of treatment with salmeterol and fluticasone propionate as well as the combination of these drugs. ${ }^{10}$ Similar fast effects were seen for formoterol and budesonide. ${ }^{11}$

We hypothesised that a large study like the TRISTAN trial would have sufficient statistical power to detect the time of onset of an effect of the individual drugs on lung function and possibly on breathlessness. To study this, we used diary card information on both daily peak expiratory flow (PEF) measurements and symptom assessments obtained during the immediate post-randomisation phase of the TRISTAN trial.

\section{METHODS}

The methods of the TRISTAN trial have been published previously. ${ }^{10}$ Briefly, it was designed to compare the efficacy of a salmeterol/fluticasone propionate combination (50/ $500 \mu \mathrm{g}$ twice daily) with salmeterol alone ( $50 \mu \mathrm{g}$ twice daily), fluticasone propionate alone $(500 \mu \mathrm{g}$ twice daily) and placebo, and to compare safety of all treatment groups. Inclusion criteria were COPD (ERS definition), age 4079 years, $>10$ pack-years, pre-bronchodilator forced expiratory volume in 1 second $\left(\mathrm{FEV}_{1}\right) 25-70 \%$ predicted, $\mathrm{FEV}_{1} /$ forced vital capacity (FVC) $<70 \%$, poor short term reversibility $\left(<10 \%\right.$ predicted $\mathrm{FEV}_{1} 30$ minutes after inhaling $400 \mu \mathrm{g}$ salbutamol), and chronic bronchitis with exacerbations in the last 3 years.

Patients with a current diagnosis of asthma, eczema, allergic rhinitis, use of systemic steroids, antibiotics, or change in COPD medication during the last 4 weeks were excluded. Patients could continue medications like short acting bronchodilators, acetylcysteine, and sodium cromoglycate provided the treatment was kept unchanged during the study; oral corticosteroids and/or antibiotics could be given in short courses for exacerbation treatment. Oral short acting $\beta_{2}$ agonists, other inhaled corticosteroids, other long acting $\beta_{2}$ agonists, and combination bronchodilators (Combivent, Berodual, Duovent) were not allowed.

The analysis was designed to identify the point at which a treatment effect was first observed in the three treatment arms of the study. Each morning patients recorded in their daily record cards the highest of three PEF values measured with a mini-Wright peak flow meter before taking any medication. They also recorded use of relief albuterol,

${ }^{\dagger}$ Deceased. 
symptom scores, and number of night-time awakenings in the previous 24 hours. Breathlessness was scored as 0 (none) to 4 (breathless at rest). We limited the period of analysis to the first 14 days after starting study medication. Clinic $\mathrm{FEV}_{1}$ was measured at randomisation, after 2 weeks, and at seven further visits for the remaining 50 weeks.

\section{Statistical methods}

The analysis of PEF on days 1-14 was performed using repeated measures analysis of covariance (ANCOVA) which controlled for multiple testing. Smoking status, age, sex, baseline lung function, and country were included in the model as covariates, day was specified as a categorical variable, and a treatment $x$ day interaction term allowed the effect of treatment to differ at each day. Breathlessness scores on each of days 1-14 were analysed using a proportional odds model for ordered categorical data. In this model an odds ratio (OR) for a given treatment describes the likelihood of patients on this treatment experiencing a one step improvement in breathlessness compared with patients on placebo. An OR of 1.5 for a given treatment would mean that the odds of a patient experiencing a one point improvement is $50 \%$ higher on this treatment compared than what the patient would experience on placebo. Both models included the covariates of smoking status, age, sex, and baseline symptom score. Clinic $\mathrm{FEV}_{1}$ was analysed using repeated measures ANCOVA. Correlations between change in PEF and $\mathrm{FEV}_{1}$ were analysed using Spearman correlation coefficients. Drop outs in the first 2 weeks were excluded from analyses. All confidence intervals (CI) cover 95\%.

\section{RESULTS}

The TRISTAN trial was conducted at 196 centres in 25 countries and recruited 1974 patients of whom 1465 received treatment. Demographic data, baseline characteristics, and compliance did not differ between treatments whereas withdrawals were significantly less frequent in all three active treatment arms than in the placebo group. Table 1 shows the baseline characteristics for the four treatment arms for the variables of interest in the present analyses.

A total of 75 patients (3.9\%) dropped out of the study in the first 2 weeks. Figure 1 shows changes in PEF from baseline in the first 2 week period. It can be seen that the PEF differed between the days $(\mathrm{p}<0.001)$ and also between the treatments $(p<0.001)$. Moreover, the difference between the treatments was not constant over the 14 days (days $\times$ treatment interaction $\mathrm{p}=0.002$ ). For salmeterol and the salmeterol/fluticasone propionate combination, PEF was significantly higher than placebo after $\mathrm{l}$ day $(\mathrm{p}<0.001$ for both), for fluticasone propionate this was the case after 2 days $(\mathrm{p}<0.001)$. After 2 weeks the difference between placebo and salmeterol, fluticasone propionate, and the

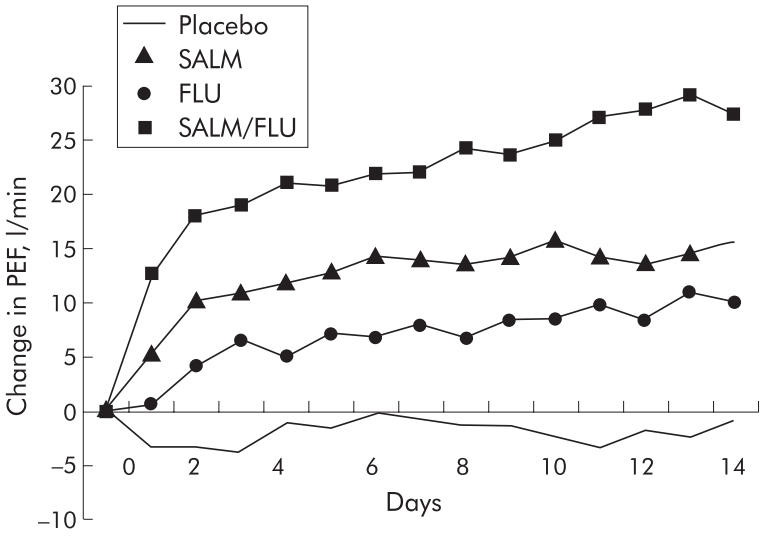

Figure 1 Changes in mean peak expiratory flow (PEF) in the four treatment arms in the first 2 weeks after randomisation.

salmeterol/fluticasone propionate combination was $16 \mathrm{l} / \mathrm{min}$ (95\% CI 11 to $21, \mathrm{p}<0.001), 11 \mathrm{l} / \mathrm{min}$ (95\% CI 6 to 16 , $\mathrm{p}<0.001)$, and $27 \mathrm{l} / \mathrm{min}(95 \%$ CI 22 to $33, \mathrm{p}<0.001)$, respectively. The change in the combination treatment group was significantly better than all other treatment groups after 1 day: difference between this group and salmeterol group was $7 \mathrm{l} / \mathrm{min}$ ( $95 \%$ CI 3 to $12, \mathrm{p}<0.001)$; for the fluticasone propionate group the difference was $12 \mathrm{l} / \mathrm{min}$ (95\% CI 8 to 16 , $\mathrm{p}<0.001$ ). As shown in fig 1 , the PEF had not quite reached a plateau in the three treatment groups after 2 weeks. Over the entire 52 weeks of treatment the difference between placebo and salmeterol, fluticasone propionate, and the salmeterol/ fluticasone propionate combination was $15 \mathrm{l} / \mathrm{min}$ (95\% CI 10 to 20 ), $13 \mathrm{l} / \mathrm{min}$ (95\% CI 8 to 19 ), and $32 \mathrm{l} / \mathrm{min}$ (95\% CI 26 to 37 ), respectively.

The effect of treatment on breathlessness was measurable slightly later, as shown in table 2 where effects after 1, 2, and 14 days are shown. After 2 weeks the change in the combination treatment group was significantly better than all other treatment groups; OR for improvement compared with the salmeterol group was 1.4 (95\% CI 1.0 to 1.9 , $\mathrm{p}=0.035)$ and compared with the fluticasone propionate group the OR was 1.7 (95\% CI 1.3 to $2.3, \mathrm{p}<0.001)$. Comparable effects were found for cough and night awakenings but not for the phlegm scores (data not shown).

Within the first 2 weeks clinic $\mathrm{FEV}_{1}$ also improved significantly. The improvement compared with placebo was $61 \mathrm{ml}(95 \%$ CI 28 to $94, \mathrm{p}<0.001), 41 \mathrm{ml}(95 \%$ CI 8 to 74 , $\mathrm{p}=0.016)$, and $147 \mathrm{ml}(95 \%$ CI 113 to $181, \mathrm{p}<0.001)$ for the salmeterol, fluticasone propionate, and salmeterol/fluticasone propionate combination, respectively. Compared with the effect of treatment at week 52, the initial improvement

Table 1 Baseline characteristics of the study population

\begin{tabular}{|c|c|c|c|c|}
\hline & $\begin{array}{l}\text { Placebo } \\
\text { ( } n=361)\end{array}$ & $\begin{array}{l}\text { Salmeterol } \\
(n=372)\end{array}$ & $\begin{array}{l}\text { Fluticasone } \\
(\mathrm{n}=374)\end{array}$ & $\begin{array}{l}\text { Combination } \\
(\mathrm{n}=358)\end{array}$ \\
\hline Withdrawal after randomisation & $140(39 \%)$ & $119(32 \%)$ & $108(29 \%)$ & $89(25 \%)$ \\
\hline Mean (SD) age (years) & $63.4(8.6)$ & $63.2(8.6)$ & $63.5(8.5)$ & $62.7(8.7)$ \\
\hline Male, $\mathrm{n}(\%)$ & $269(75 \%)$ & $261(70 \%)$ & $260(70 \%)$ & $270(75 \%)$ \\
\hline Current smoker, n (\%) & $171(47 \%)$ & $191(51 \%)$ & $198(53 \%)$ & $186(52 \%)$ \\
\hline Mean (SD) pack years smoked & $43.4(22.4)$ & $43.7(21.9)$ & $41.5(20.7)$ & $42.0(22.4)$ \\
\hline Previous ICS use, $\mathrm{n}(\%)$ & $188(52 \%)$ & $183(49 \%)$ & $202(54 \%)$ & $178(50 \%)$ \\
\hline Previous LABA use, $\mathrm{n}(\%)$ & $136(38 \%)$ & $156(42 \%)$ & $148(40 \%)$ & $151(42 \%)$ \\
\hline $\begin{array}{l}\text { Mean (SD) pretreatment } \mathrm{FEV}_{1} \\
\text { (\% predicted) }\end{array}$ & $44.2(13.7)$ & $44.3(13.8)$ & $45.0(13.6)$ & $44.8(14.7)$ \\
\hline Mean (SD) PEF (I/min) & $243(89)$ & $235(90)$ & $246(90)$ & $247(93)$ \\
\hline
\end{tabular}


Table 2 Effects of treatments on breathlessness

\begin{tabular}{|c|c|c|c|c|c|c|c|c|c|}
\hline & \multicolumn{3}{|c|}{ Day 1} & \multicolumn{3}{|c|}{ Day 2} & \multicolumn{3}{|c|}{ Day 14} \\
\hline & OR & $95 \% \mathrm{Cl}$ & $p$ value & OR & $95 \% \mathrm{Cl}$ & $p$ value & $\overline{O R}$ & $95 \% \mathrm{Cl}$ & $p$ value \\
\hline Placebo & 1 & - & - & 1 & - & - & 1 & - & - \\
\hline Salmeterol & 1.40 & 1.04 to 1.87 & 0.025 & 1.55 & 1.16 to 2.06 & 0.003 & 1.57 & 1.17 to 2.12 & 0.003 \\
\hline Fluticasone propionate & 0.90 & 0.68 to 1.21 & 0.497 & 1.06 & 0.80 to 1.41 & 0.679 & 1.28 & 0.95 to 1.72 & 0.111 \\
\hline $\begin{array}{l}\text { Salmeterol/fluticasone } \\
\text { propionate combination }\end{array}$ & 1.22 & 0.91 to 1.64 & 0.184 & 2.05 & 1.53 to 2.76 & $<0.001$ & 2.19 & 1.60 to 2.98 & $<0.001$ \\
\hline
\end{tabular}

Effects of treatments on odds of decreasing breathlessness by one step on a 4-point scale.

Odds ratios (OR) for active treatment to placebo are given with $95 \%$ confidence intervals and $p$ values.

represented $113 \%, 79 \%$, and $94 \%$, respectively, of the overall effect. Due to the large number of measurements, the change in $\mathrm{FEV}_{1}$ at 14 days was significantly correlated with the change in PEF at 14 days $(\mathrm{p}<0.0001)$, but with a small $r$ value $(r=0.23)$.

After 2 weeks the mean $\mathrm{FEV}_{1}$ had increased in all four groups; the increase was $16 \mathrm{ml}$ in the placebo group, $76 \mathrm{ml}$ in the salmeterol group, $55 \mathrm{ml}$ in the fluticasone propionate group, and $163 \mathrm{ml}$ in the salmeterol/fluticasone propionate combination group. Table 3 shows median, 25th and 75th percentiles for the increase in $\mathrm{FEV}_{1}$ in each of the four treatment groups after 2 and 52 weeks. In order to see if the change at week 2 predicted long term change, we looked at patients in the highest quartile in each of the treatment groups after 2 weeks; for this analysis only those who completed 52 weeks of treatment were included. Table 3 shows the change in $\mathrm{FEV}_{1}$ after 2 and 52 weeks expressed as median, 25th and 75th percentiles. For the salmeterol/ fluticasone propionate combination group the 75 th percentile was $280 \mathrm{ml}$, a substantial increase. After 52 weeks 55\% of those initially in this highest quartile remained in the upper quartile and $74 \%$ were in the upper two quartiles-that is, they had an increase in $\mathrm{FEV}_{1}$ at 52 weeks of $80 \mathrm{ml}$ or more. The comparable percentages remaining in the highest quartile and upper half did not differ markedly for the other groups although their actual change in $\mathrm{FEV}_{1}$ was, of course, smaller than in the combination treatment group. Conversely, in the salmeterol/fluticasone propionate combination group only $8 \%$ of those initially in the highest quartile ended up in the lowest quartile after 52 weeks and 10\% moved from the lowest quartile to the highest within a year.

\section{DISCUSSION}

There is increasing recognition that studies of 1 year or more are needed to evaluate properly the effect of treatment in $\mathrm{COPD}^{3}{ }^{10}{ }^{11}$ but little is known about how quickly treatment works in COPD and whether combining treatments influences the speed of onset of action. In this study we report a rapid onset of action of treatment with salmeterol and a salmeterol/fluticasone propionate combination and, to some extent, with fluticasone propionate alone. The effects of treatment on PEF were apparent within a few days and comparable to the final effects of treatment. Scores for breathlessness also improved quickly and treatment effects were apparent within 2 days in this disease hitherto considered unresponsive.

An effect of salmeterol on lung function in COPD has previously been shown to be apparent within 2 hours of the first dose, ${ }^{12}$ and the time to onset of the bronchodilator effects in COPD does not differ substantially from that seen in asthma. The changes in PEF we report at 24 hours are identical to those seen in a smaller population of similar severity. ${ }^{13}$ It is, however, surprising that the effects of fluticasone propionate either alone or when combined with salmeterol become apparent within 1-2 days of treatment. A recent study comparing the effect of formoterol alone or in combination with budesonide within 60 minutes of inhalation $^{14}$ found a more rapid bronchodilatation from formoterol when given together with budesonide. Because of the short time span, the authors ascribed this to non-genomic effects. It is unclear if this very early effect which was not sensed by the patients relates to our findings. Changes in PEF were mirrored by changes in $\mathrm{FEV}_{1}$ seen after 2 weeks at the first measurement made after randomisation; ${ }^{10}$ this was seen in all three treatment arms. This initial increase in $\mathrm{FEV}_{1}$ after 2 weeks was similar to the initial change seen in EUROSCOP, ${ }^{15}$ the estimated change in the statistical modelling used in ISOLDE, ${ }^{2}$ and in the recent study by Szafranski $e t$ al. ${ }^{11}$ However, no initial effect was seen in the Copenhagen City Lung Study ${ }^{16}$ or the Lung Health Study, ${ }^{4}$ so differences in severity of COPD are unlikely to be the sole explanation.

The $\mathrm{FEV}_{1}$ is the standard measure of airway function in COPD $^{1}$ and most treatments in COPD have been evaluated using $\mathrm{FEV}_{\mathrm{l}}$ as the effect parameter. PEF may have more limitations but has a predictive power comparable to that of $\mathrm{FEV}_{1}$ in COPD. ${ }^{17}$ In this study we have shown statistically significant changes in PEF which at first sight appear to be small. However, the changes seen in these analyses are not small. The proportional changes from baseline were comparable to those seen in $\mathrm{FEV}_{1}$. Changes of 15-30 l/min are not different from changes seen when comparing inhaled corticosteroids with placebo in mild stable asthma; in a recent Cochrane review the mean increase in chronic asthma for fluticasone propionate compared with placebo was 29-

Table 3 Change in $\mathrm{FEV}_{1}$ (in $\mathrm{ml}$ ) after 2 and 52 weeks in each of the four treatment groups expressed as median, 25th and 75th percentiles

\begin{tabular}{|c|c|c|c|c|c|c|c|c|}
\hline & \multicolumn{4}{|c|}{2 weeks } & \multicolumn{4}{|c|}{52 weeks } \\
\hline & $\mathbf{N}$ & Median & $25^{\text {th }}$ percentile & $75^{\text {th }}$ percentile & $\mathbf{N}$ & Median & $25^{\text {th }}$ percentile & $75^{\text {th }}$ percentile \\
\hline $\begin{array}{l}\text { Placebo } \\
\text { Salmeterol } \\
\text { Fluticasone } \\
\text { Salmeterol/fluticasone } \\
\text { combination }\end{array}$ & $\begin{array}{l}348 \\
352 \\
365 \\
343\end{array}$ & $\begin{array}{r}0 \\
60 \\
50 \\
140\end{array}$ & $\begin{array}{l}-100 \\
-35 \\
-80 \\
0\end{array}$ & $\begin{array}{l}100 \\
180 \\
150 \\
280\end{array}$ & $\begin{array}{l}216 \\
255 \\
267 \\
269\end{array}$ & $\begin{array}{l}-65 \\
0 \\
0 \\
80\end{array}$ & $\begin{array}{l}-200 \\
-130 \\
-160 \\
-50\end{array}$ & $\begin{array}{r}85 \\
140 \\
160 \\
250\end{array}$ \\
\hline
\end{tabular}


$49 \mathrm{l} / \mathrm{min}$ depending on dose. ${ }^{18}$ In this study, however, we were able to study changes in $\mathrm{FEV}_{1}$ after 2 weeks as well. We looked at these changes and tried to determine whether the initial change could predict changes after 1 year. Although not all initial responders had a sustained benefit, there was a strong tendency for the initial response to be related to sustained improvement. Given the variation in the measurement of $\mathrm{FEV}_{1}$, a weak association was to be expected. It seems unlikely that the initial response using any lung function measure or biomarker is able to fully identify long term benefits and the notion of a single dichotomy "responder/non-responder" is not biologically plausible. Initial response is only one of the parameters the patient and clinician can use to establish if long term treatment is desirable. This is similar to the situation for many treatments in chronic diseases.

Lung function, however closely linked to our understanding of the natural history of COPD, is a surrogate marker. The core symptom of COPD is breathlessness and our measurements of breathlessness were obtained using a simple diary card score. This methodology has not been validated in terms of the significance of differences in score, but is a valid method of identifying the time points at which changes in breathlessness occurred and for making comparisons between treatments in terms of the point at which differences occurred. In a previous study, changes in lung function in COPD patients after salmeterol were paralleled by reductions in the intensity of dyspnoea occurring within 120 minutes of the first dose. ${ }^{12}$ The most likely mechanism was an increase in inspiratory capacity and the most favourable response was seen in patients who had a reduction in $\mathrm{FEV}_{1}$ comparable to that in our study population. The bronchodilator induced lung deflation obtained with salmeterol also increases exercise endurance. ${ }^{19}$

In conclusion, these analyses have shown that combination treatment with an inhaled corticosteroid and a long acting $\beta$ agonist can provide benefits within days. That mean improvement is sustained over the subsequent year.

\section{Authors' affiliations}

J Vestbo, North West Lung Centre, Wythenshawe Hospital, Manchester, UK

R Pauwels, Department of Respiratory Diseases, Ghent University Hospital, Ghent, Belgium

J A Anderson, Statistics and Programming, Biomedical Data Sciences, GlaxoSmithKline Research and Development, Greenford, UK

P Jones, St George's Hospital Medical School, London, UK

P Calverley, Department of Medicine, University Hospital Aintree, Liverpool, UK

Funding for this study (protocol number SFC3024) was provided by GlaxoSmithKline.

Presented at the 2003 American Thoracic Society Annual Congress in Seattle, USA.
Salmeterol/fluticasone propionate combination ${ }^{\top M}$, Advair $^{\top M}$, and Diskus $^{\text {TM }}$ are trade names belonging to the GlaxoSmithKline group of companies.

\section{REFERENCES}

1 Pauwels R, Buist A, Calverley $P$, et al. Global strategy for the diagnosis, management and prevention of chronic obstructive pulmonary disease. NHLBI/WHO global initiative for chronic obstructive lung disease (GOLD) workshop summary. Am J Respir Crit Care Med 2001;163:1256-76.

2 Burge PS, Calverley PMA, Jones PW, et al. Randomised, double-blind, placebo controlled study of fluticasone propionate in patients with moderate to severe chronic obstructive pulmonary disease; the ISOLDE trial. BMJ 2000;320: 1297-303.

3 Spencer S, Calverley PM, Sherwood Burge P, et al. Health status deterioration in patients with chronic obstructive pulmonary disease. Am J Respir Crit Care Med 2001;163:122-8.

4 The Lung Health Study Group. Effect of inhaled triamcinolone on the decline in pulmonary function in chronic obstructive pulmonary disease. N Engl J Med 2000;343:1902-9.

5 Boyd G, Morice AH, Pounsford JC, et al. An evaluation of salmeterol in the treatment of chronic obstructive pulmonary disease (COPD). Eur Respir J 1997; 10:815-21.

6 Rennard SI, Anderson W, ZuWallack R, et al. Use of a long-acting inhaled beta $_{2}$-adrenergic agonist, salmeterol xinafoate, in patients with chronic obstructive pulmonary disease. Am J Respir Crit Care Med 2001; 163:1087-92.

7 Dahl R, Greefhorst LA, Nowak D, et al. Inhaled formoterol dry powder versus ipratropium bromide in chronic obstructive pulmonary disease. Am J Respir Crit Care Med 2001;164:778-84.

8 Vincken W, van Noord JA, Greefhorst AP, et al. Improved health outcomes in patients with COPD during 1 yr's treatment with tiotropium. Eur Respir J 2002; 19:209-16

9 Casaburi R, Mahler DA, Jones PW, et al. A long-term evaluation of once-daily inhaled tiotropium in chronic obstructive pulmonary disease. Eur Respir $J$ 2002;19:217-24.

10 Calverley P, Pauwels R, Vestbo J, et al. Combined salmeterol and fluticasone in the treatment of chronic obstructive pulmonary disease: a randomised controlled trial. Lancet 2003;361:449-56.

11 Szafranski W, Cukier A, Ramirez A, et al. Efficacy and safety of budesonide/ formoterol in the management of chronic obstructive pulmonary disease. Eur Respir J 2003;21:74-81.

12 Di Marco F, Milic-Emili J, Boveri B, et al. Effect of inhaled bronchodilators on inspiratory capacity and dyspnoea at rest in COPD. Eur Respir J 2003;21:86-94.

13 Ulrik CS. Efficacy of inhaled salmeterol in the management of smokers with chronic obstructive pulmonary disease: a single centre randomised, double blind, placebo controlled, crossover study. Thorax 1995:50:750-4.

14 Cazzola M, Santus P, Di Marco F, et al. Onset of action of formoterol/ budesonide in single inhaler vs. formoterol in patients with COPD. Pulm Pharmacol Ther 2004;17:121-5.

15 Pauwels RA, Löfdahl C-G, Laitinen LA, et al. Long-term treatment with inhaled budesonide in persons with mild chronic obstructive pulmonary disease who continue to smoke. N Engl J Med 1999;340:1948-53.

16 Vestbo J, Sørensen T, Lange $P$, et al. Long-term effect of inhaled budesonide in mild and moderate chronic obstructive pulmonary disease: a randomised, controlled trial. Lancet 1999;353:1819-23.

17 Hansen EF, Vestbo J, Phanareth K, et al. Peakflow as predictor of overall mortality in asthma and chronic obstructive pulmonary disease. Am J Respir Crit Care Med 2001;163:690-3.

18 Adams N, Bestall J, Jones PW. Inhaled fluticasone proprionate for chronic asthma (Cochrane Review). In:The Cochrane Library.Issue 4. Chichester, UK: John Wiley \& Sons, 2003.

19 O'Donnell DE, Voduc N, Fitzpatrick M, et al. Effect of salmeterol on the ventilatory response to exercise in chronic obstructive obstructive pulmonary disease. Eur Respir J 2004;24:86-94. 